\title{
Efficient Stool Collection Methods for Evaluating the Diarrhea Score in Mouse Diarrhea Models
}

\author{
SUNG KYUN YIM ${ }^{1,2}$, SANG WOOK KIM ${ }^{1,2}$ and SOO TEIK LEE ${ }^{1,2}$ \\ ${ }^{1}$ Division of Gastroenterology and Hepatology, Department of Internal Medicine, \\ Jeonbuk National University Medical School and Hospital, Jeonju, Republic of Korea; \\ ${ }^{2}$ Research Institute of Clinical Medicine, Jeonbuk National University, Jeonju, Republic of Korea
}

\begin{abstract}
Background/Aim: The mouse diarrhea score is usually determined by evaluating stool consistency and shape. Thus, defecated stools should be collected without damage or contamination. The study aimed to develop improved mouse stool collection methods and diarrheascoring criteria. Materials and Methods: We developed improved stool collection methods (paper towel methods) and compared them with previously used ones (stool collection using regular cages containing bedding chips or filter paper and metabolic cages). Results: Compared to previously used methods, paper towel methods collected stools without bedding chips-induced contamination, mouse body/foot-induced damage, or sampling errors. When using paper towel methods, wet stools create water marks (diarrhea marks) on paper towels with strong water absorption capacity, by which diarrheal severity can be analyzed semi-quantitatively. To improve the objectivity in determining diarrhea scores, practical diarrhea-scoring criteria were also proposed. Conclusion: These results would be helpful to researchers facing difficulties in evaluating the mouse diarrhea score.
\end{abstract}

Mouse models have been used to study various diarrheal diseases (1-69). In many studies employing mouse diarrhea models, the diarrhea score is usually determined on the defecated stool to compare the severity of diarrhea between experimental groups (1-66). The diarrhea score is determined by scoring various parameters graded in 2 -

This article is freely accessible online.

Correspondence to: Soo Teik Lee, MD, Ph.D., Division of Gastroenterology and Hepatology, Department of Internal Medicine, Jeonbuk National University Medical School, 20 Geonjiro, Deokjingu, Jeonju, Jeollabukdo 54907, Republic of Korea. Tel: +82 632501684, Fax:+82 632541609, e-mail: soo@jbnu.ac.kr

Key Words: Diarrhea, method, mouse, score, stool.
5 steps according to the severity of diarrhea (1-69). Parameters frequently employed in evaluating the diarrhea score were stool consistency, stool stickiness, stool water content, stool shape, the presence of mucus or blood, diarrhea-induced fur staining, and body weight reduction (1-69).

All parameters described above, except for diarrheainduced fur staining and body weight reduction, can only be evaluated when feces are properly collected. To correctly evaluate the severity of diarrhea on the stool, defecated feces should be collected without damage caused by external factors such as contamination by bedding chips or crushing by being stepped on by the mouse foot and body.

We recently evaluated the diarrhea score in a study using a mouse model of 5-fluorouracil (5-FU)-induced diarrhea (70). When we tried to collect feces during the study, we encountered difficulties in collecting intact feces by using regular mouse cages containing bedding chips, because many defecated feces were contaminated or damaged by the bedding chips or the foot and body of the moving mice. It was also difficult to evaluate the diarrhea score on the stool stuck to the bedding chips. Moreover, it was often difficult to determine the exact grade for the parameters employed in evaluating the diarrhea score, because of the overlapping ambiguous boundaries between grades described in many previous studies $(2,5,6,17,22)$.

In the present study, we searched the literature published in the last five years reporting the results of the mouse diarrhea score and identified the drawbacks of the previously used stool collection methods and criteria for determining the diarrhea score. Consequently, in this study, we aimed to propose improved methods for stool collection (paper towel methods which can collect defecated stools with little damage). More practical criteria and procedures for grading the diarrhea score on defecated stools are also proposed with clear boundaries between grades. The results can be helpful to researchers who encounter difficulties in evaluating the severity of diarrhea in experimental mouse models. 


\section{Materials and Methods}

Mice. Specific pathogen-free BALB/c mice (6-8 weeks of age) were purchased (Damul Experimental Animal Center, Daejeon, Republic of Korea) and housed in steel wire net-covered plastic cages containing bedding chips (Damul Experimental Animal Center) (regular cage) at the Jeonbuk National University Hospital Animal Care Facility. Mice were maintained under a $12 \mathrm{~h}$ dark-light cycle at a temperature of 20$22^{\circ} \mathrm{C}$ (45-70\% humidity) and fed on food and water ad libitum. Mice were age- and sex-matched at the onset of each experiment. Experimental protocols were approved by the Jeonbuk National University Animal Care and Use Committee (JBNU 2020-047).

Mouse diarrhea models. We employed two types of mouse diarrhea models, the 5-FU-induced diarrhea model and the castor oil-induced diarrhea model. These two models have different characteristics of diarrhea. Compared with the 5-FU-induced diarrhea model, the castor oil-induced diarrhea model has the characteristics of faster induction of diarrhea, shorter duration of diarrhea, and more frequent watery diarrhea. By employing two different diarrhea models, the present study attempted to increase the potential that the experimental results could be applied to different mouse diarrhea models having various diarrheal characteristics.

In the 5-FU-induced diarrhea model, 5-FU (Ildong Pharmaceutical Co., Seoul, Republic of Korea) was intraperitoneally injected at a dose of $30 \mathrm{mg} / \mathrm{kg}$ body weight daily for 5 consecutive days (days 15). In the castor oil-induced diarrhea model, castor oil (Merck, Seoul, Republic of Korea) was administered at a dose of $20 \mathrm{ml} / \mathrm{kg}$ body weight as a single dose by using oral gavage.

Comparison of stool collection methods. The stool collection methods employed in searched studies and the "paper towel method" devised by the authors were compared in terms of the degree of damage to the stools collected. In some experiments, differences in convenience between the stool collection methods were also checked.

Comparison of water marks. Using a micropipette, aliquots of 20 $\mu \mathrm{l}$ of water were instilled in triplicate on the paper towel (YuhanKimberly, Seoul, Republic of Korea) and the filter paper (Sartorius Stedim Biotech, Seoul, Republic of Korea). The longest diameter of the water mark generated on them by the instilled water was measured after 2 min.

Statistical analysis. Data are expressed as mean \pm standard deviation (SD). Differences between two groups were analyzed by Student's $t$-test. Data were analyzed with SPSS statistics 23 (IBM, USA) and graphed using Microsoft Excel 2010 (Microsoft, USA). $p<0.05$ (two-sided tests) was considered statistically significant.

\section{Results}

Feces collection methods employed in the searched literature. Most studies did not have specific descriptions of the feces collection method, and were considered to have collected feces in regular cages containing bedding chips. There were only 7 studies that described the feces collection method (Table I). In three of the seven studies, a filter paper was placed on the cage floor without bedding chips to collect
Table I. Feces collection methods described in the searched literature.

\begin{tabular}{lc}
\hline Methods & $\begin{array}{c}\text { Number } \\
\text { of studies }\end{array}$ \\
\hline $\begin{array}{l}\text { No description or regular cage with bedding chips } \\
\text { Regular cage with filter papers laid on the floor } \\
\text { (no bedding chips) }\end{array}$ & 39 \\
Regular cage with paper towels laid on bedding chips & 1 \\
Metabolic cage & 1 \\
Holding the mouse in the hand & 2 \\
\hline
\end{tabular}

stools, and the severity of diarrhea was determined by measuring the size of the diarrhea marks formed on the filter paper $(20,63,64)$. In one study, the bedding chips of the cage were covered with white paper towels to observe the bloody feces (65). In another study, feces were collected using a metabolic cage (62), and in the other two studies, the severity of diarrhea was evaluated on stools defecated while holding the mouse in the hand $(19,66)$.

Among the feces collection methods searched from the literature, 1) one using bedding chips-containing regular cages, 2) one using regular cages having a paper towel on the floor instead of bedding chips (As a representative method of one using cages having a filter paper on the cage floor without bedding chips and one using regular cages having a paper towel on the bedding chips), and 3) one using metabolic cages, were compared with the "paper towel method" devised by the authors in terms of the capability of collecting intact stools without damage. The method evaluating defecated feces while holding the mouse in the hand was excluded from the comparison experiments because it was considered unsuitable for its use in usual experiments dealing with a large number of mice.

Parameters employed in evaluating the diarrhea score in the searched literature. The parameters for evaluating the severity of diarrhea employed in the searched studies were stool consistency, stool stickiness, stool wetness (stool water content), stool shape, and the presence of occult or gross blood and mucus (1-66). In some studies, the severity of diarrhea was evaluated by observing the size of fur coat staining caused by diarrhea $(3,6,8)$.

Parameters such as stool consistency, stool stickiness, stool wetness (stool water content), and stool shape are simultaneously affected by the water content of the stool. All these parameters were considered to be the same even though they have different expressing terms. "Stool consistency" was therefore employed as the term representing all these parameters unless otherwise noted.

Paper towel method. To correctly evaluate the severity of diarrhea on feces, feces should be observed without being 


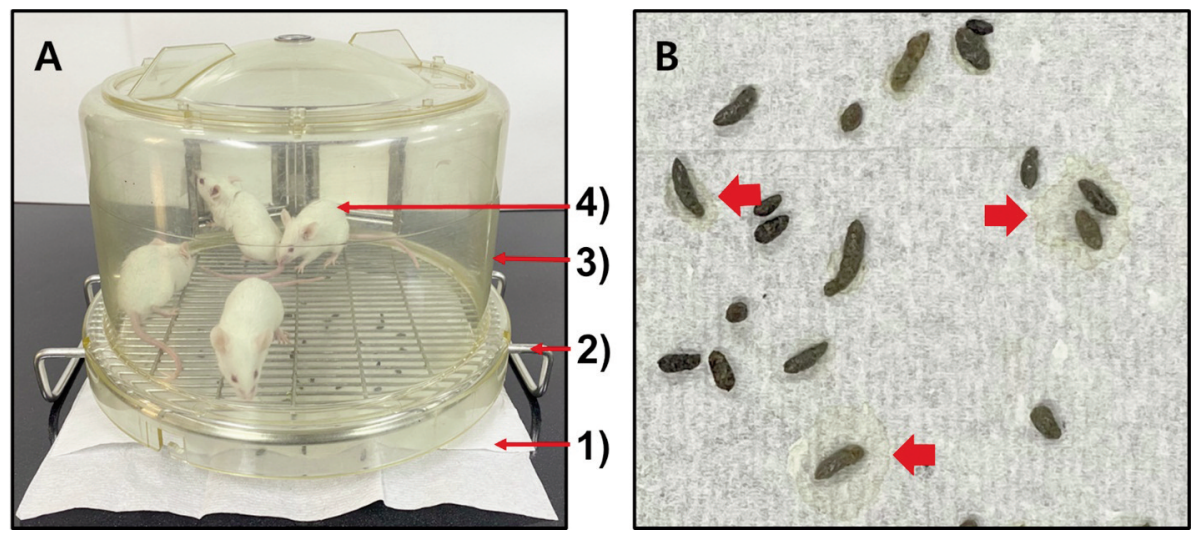

Figure 1. The paper towel method. The paper towel method was performed as follows (A). 1) Place paper towels on the experiment table. 2) Put the steel wire net floor (the bottom part of the mouse-dwelling portion of the metabolic cage) upside down on the paper towels. 3) Place the upper plastic cage (the upper plastic part of the mouse-dwelling portion of the metabolic cage) on the steel wire net floor. 4) Place mice in the cage and evaluate defecated stools seated on the paper towel by being dropped down through the steel wire net for required periods. Note water marks or diarrhea marks (thick arrows) generated on the paper towel by wet stools collected from mice of the 5-FU-induced diarrhea model on day 11 (B).

damaged by external factors such as bedding chips or mouse foot and body. Since many studies employed stool consistency (closely related to stool wetness or water content) as an important parameter for evaluating the diarrhea score, collecting feces on a paper towel with good water absorption capability would be useful. In other words, if the water mark (diarrhea mark) generated on the paper towel by the wetness of stools was observed, it would be more objective than judging the wetness on the stool itself with the naked eyes only. The paper towel method was therefore devised as a method for collecting feces with the merits (Figure 1A). The paper towel method was performed as follows: 1) Place paper towels on the experiment table. 2) Put the steel wire net floor (the bottom part of the mouse-dwelling portion of the metabolic cage, Nalgene, Rochester, NY, USA) upside down on the paper towels. This creates a gap of about $2 \mathrm{~cm}$ between the steel wire net and the paper towel. Therefore, defecated stools dropped on the paper towel can be evaluated without damages caused by being stepped on by the mouse foot or body. 3) Place the upper plastic cage (the upper plastic part of the mouse-dwelling portion of the metabolic cage) on the steel wire net floor. 4) Place mice in the cage and evaluate defecated stools seated on the paper towel by being dropped down through the steel wire net for required periods. By using this method, the contamination or damage of feces caused by bedding chips or mouse foot and body can be prevented. Also, wet feces can show water marks or diarrhea marks on the paper towel due to the strong water absorption capability of the paper towel. The water mark can help determine the consistency/wetness of feces (thick arrows in Figure 1B).

The size of water absorption marks (water marks) on the paper towel vs. the filter paper. In some previous studies, the severity of diarrhea was evaluated by collecting feces on the filter paper and comparing the size of the water mark (diarrhea mark) generated on the filter paper by absorbing water from wet feces $(20,63,64)$. We evaluated whether the paper towel generates larger or better evaluable water absorption marks (water marks) than the filter paper. The longest diameter of the water marks generated on the paper towel $(2.3 \pm 0.1 \mathrm{~cm})$ was larger than that on the filter paper $(1.6 \pm 0.0 \mathrm{~cm}, p<0.001)$ (Figure 2). This result led us to use the paper towel instead of the filter paper in the paper towel method.

The stool collection method using regular cages vs. the paper towel method. In a regular cage containing four mice of the 5FU-induced diarrhea model, the bedding chips were replaced with new ones on day 8 , and defecated feces were observed after $1 \mathrm{~h}$. As shown in Figure 3A, many feces stuck to the bedding chips. Although the feces sticking to the bedding chips were judged to be diarrheal ones, stool consistency and shape were hard to be determined due to the bedding chips stuck to the feces. On the other hand, when the defecated feces were collected for $1 \mathrm{~h}$ using the paper towel method, most of them were evaluable for the shape as well as the consistency/wetness (Figure 3B). In particular, the consistency/wetness of the stool was easily identified due to the water mark generated on the paper towel by the moisture in the stool (arrows in Figure 3B).

The stool collection method using cages having the paper towel placed on its floor vs. the paper towel method. In a regular cage containing four mice of the 5-FU-induced diarrhea model, the bedding chips were removed on day 8 , and a paper towel was placed on the cage floor, and defecated feces were observed after $1 \mathrm{~h}$. As shown in Figure $4 \mathrm{~A}$, it was hard to determine the shape and consistency of 

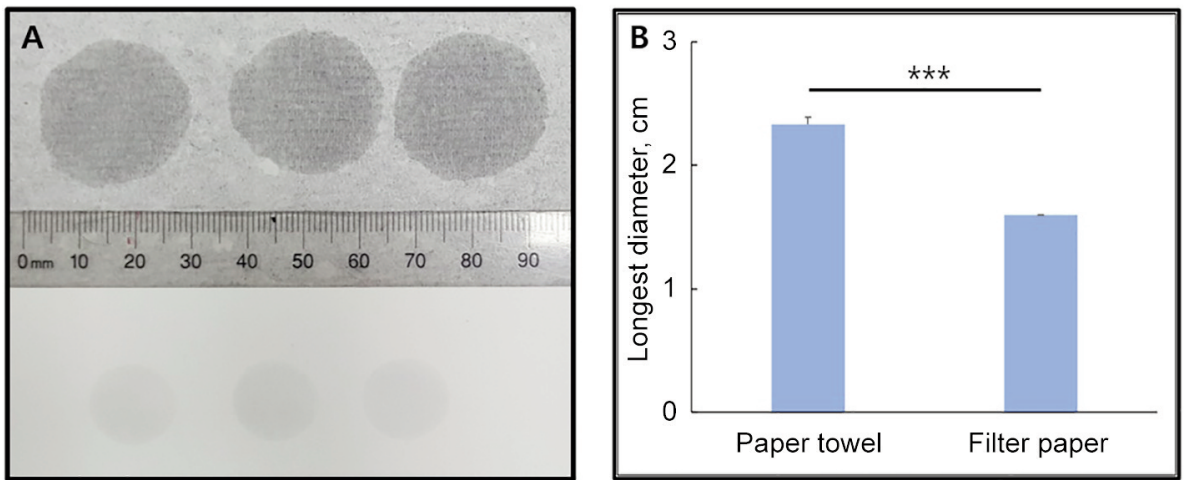

Figure 2. Differences in the size of water marks generated by the instilled water between the paper towel and the filter paper. Two minutes after instilling aliquots of $20 \mu \mathrm{l}$ of water on the paper towel (A, upper) and the filter paper (A, lower), the longest diameter of the water marks generated on them was measured. A representative picture $(A)$ and mean $\pm S D$ of the sizes of the water marks $(B)$ are presented. $* * * p<0.001$.
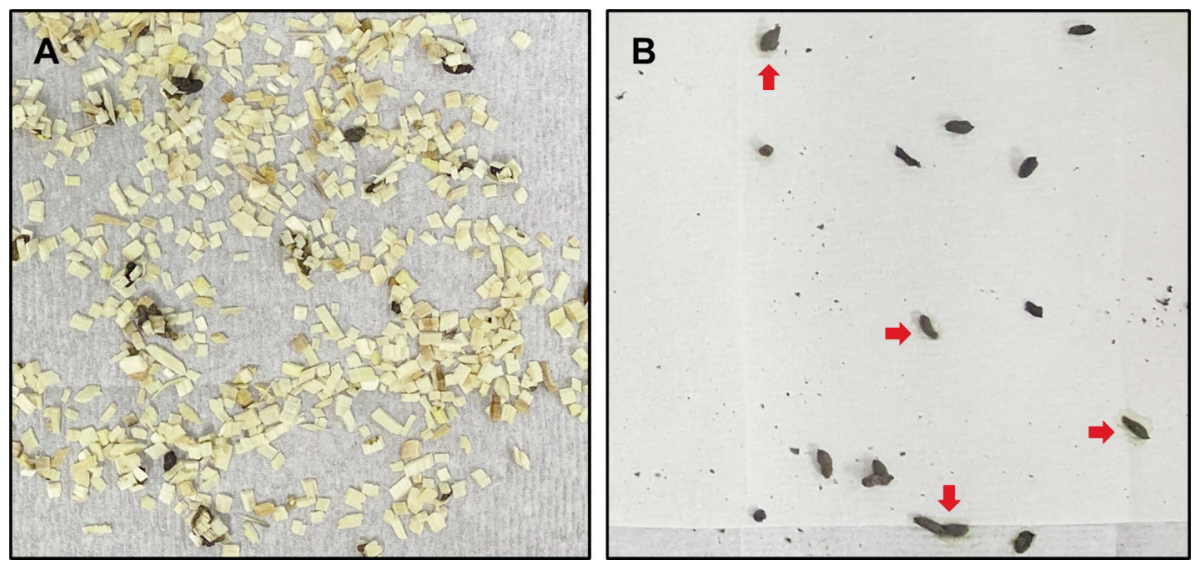

Figure 3. Stools collected by using the regular cage containing bedding chips (A) vs. the paper towel method (B). Defecated stools were collected from mice of the 5-FU-induced diarrhea model on day 8. Note water marks or diarrhea marks (red arrows) generated on the paper towel by wet stools (B).

the feces because the feces were crushed by being stepped on by the foot and body of the mice. In contrast, when feces were collected for $1 \mathrm{~h}$ using the paper towel method, the consistency/wetness and shape of the feces could be determined with fewer difficulties (Figure 4B).

The stool collection method using the fully equipped metabolic cage vs. the paper towel method. Four mice were placed in a fully equipped metabolic cage $1 \mathrm{~h}$ after the oral administration of castor oil and feces were collected for $2 \mathrm{~h}$. As shown in Figure 5, only a small fraction of defecated feces which have normal shapes and low stickiness were collected in the feces collection tube, and the remained large fraction of defecated feces were stuck on the sliding down side wall of the metabolic cage. Therefore, the evaluation of the feces was difficult when using the fully equipped metabolic cage compared with when using the paper towel method. It was also more inconvenient than the paper towel method because it took more time to assemble/disassemble and clean the parts of the cage. Besides, not only a small fraction of feces were collected in the feces collection tube, but it was also difficult to evaluate feces in situ within the tube. Therefore, the feces must be moved out of the tube for evaluation. The feces could be damaged during the moving out process, especially when the feces were sticky. On the other hand, when the paper towel method (using only the mouse-dwelling portion of the metabolic cage) was employed, the shape and consistency/wetness of the feces could be determined with fewer difficulties.

Modification of the paper towel method. The paper towel method requires the mouse-dwelling portion of the metabolic cage including a steel wire net (although not a fully equipped metabolic cage) (Figure 6A). However, there are laboratories that do not have metabolic cages. For such laboratories, two modified paper towel methods were devised in the present 

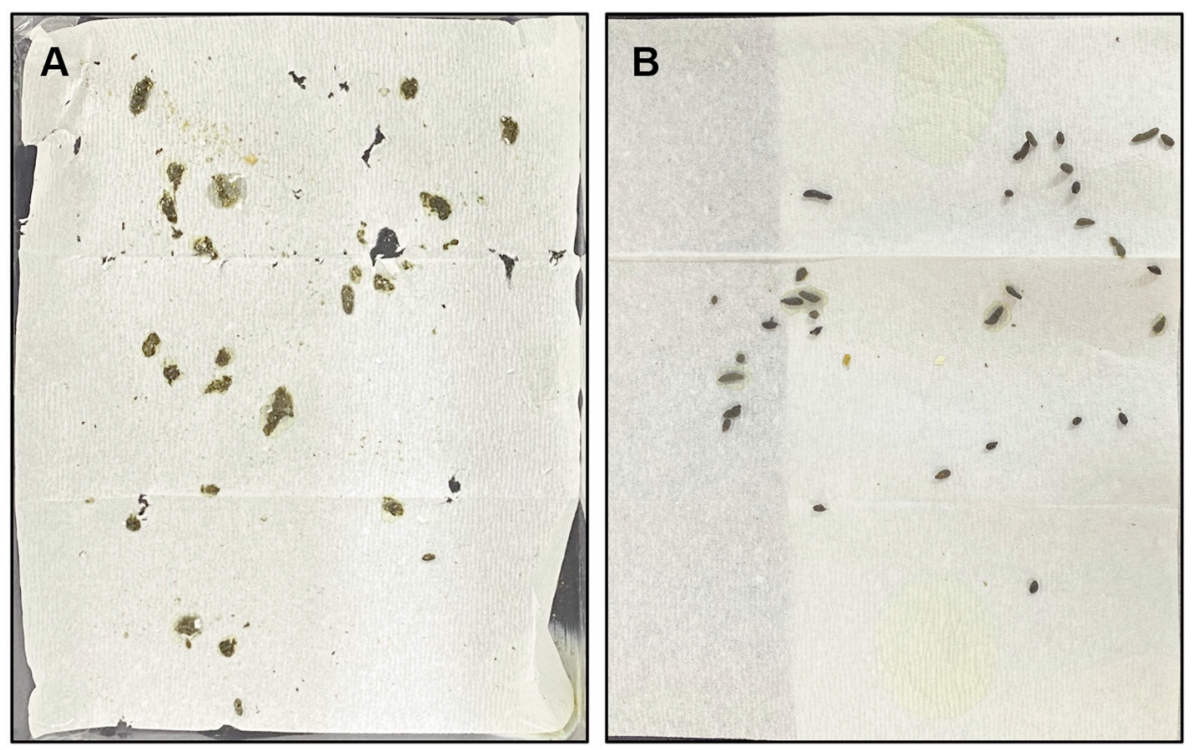

Figure 4. Stools collected by using the cage having a paper towel placed on its floor $(A)$ vs. the paper towel method (B). Defecated stools were collected from mice of the 5-FU-induced diarrhea model on day 8.
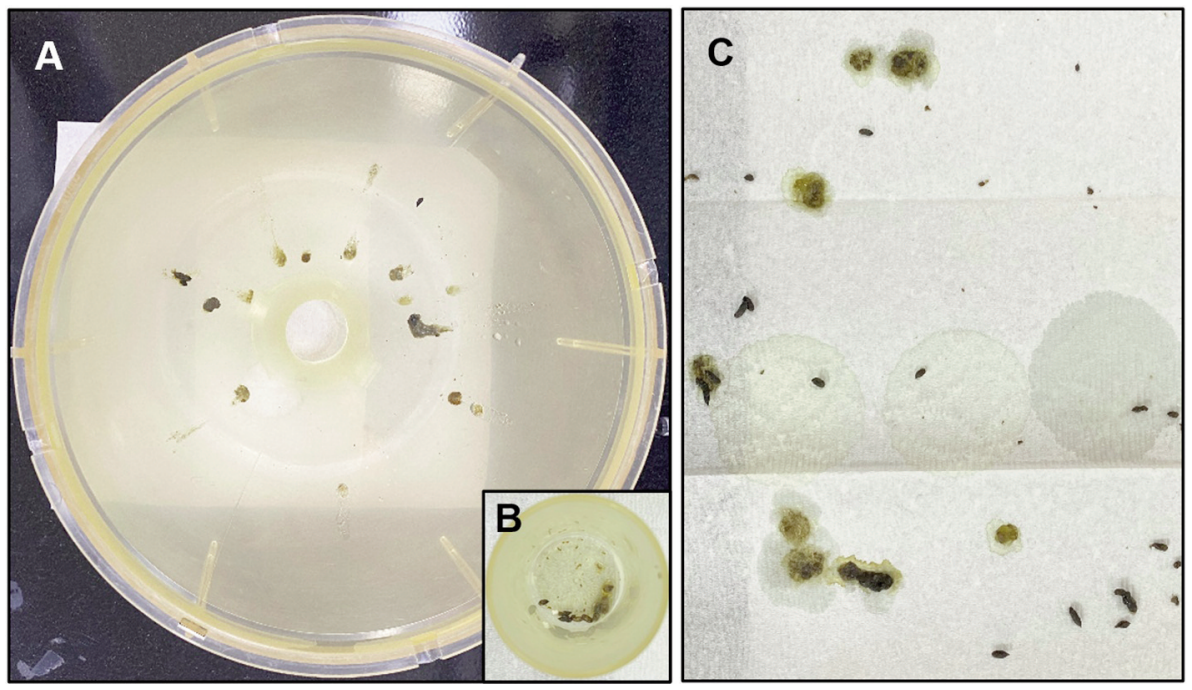

Figure 5. Stools collected by using the fully equipped metabolic cage [sliding down side wall (A) and feces collection tube (B)] vs. the paper towel method $(C)$. Defecated stools were collected for $2 \mathrm{~h}$ from mice, $1 \mathrm{~h}$ after the oral administration of castor oil.

study. First, the regular cage was placed upside down on pedestals (Two test tube racks were employed as pedestals) laid on the paper towel (Figure 6B). Second, only the plastic part of the regular cage was placed upside down on a steel wire net (gridiron, etc.) put on pedestals (Two test tube racks were employed as pedestals) laid on the paper towel (Figure 6C).

Defecated feces were collected and observed by using the two modified paper towel methods. The paper towel method served as a control. Four mice of the 5-FU-induced diarrhea model were employed for each method on day 9. The two modified paper towel methods showed comparable performance in evaluating stools to the paper towel method in terms of the capability of collecting intact stools without damage (Figure 6D-F).

\section{Discussion}

In studies employing mouse diarrhea models, the severity of diarrhea was assessed by using a variety of diarrhea scores (169). The parameters for evaluating the diarrhea scores were stool consistency (wetness, stickiness, water content), stool shape, and 

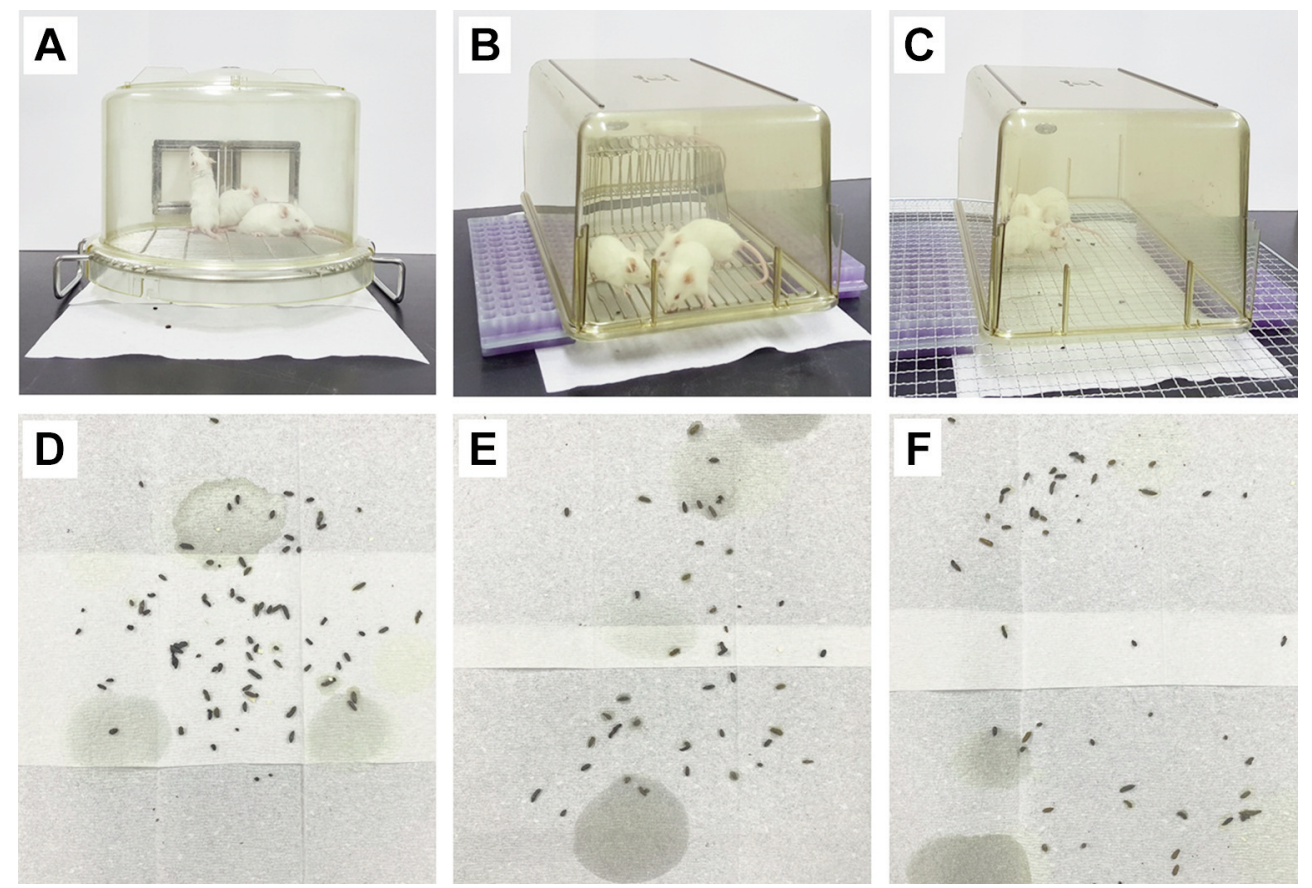

Figure 6. The paper towel method (A), modified paper towel methods (B and $C)$, and stools $(D, E$, and $F)$ collected by using them (A, B, and $C$, respectively). Defecated stools were collected from mice of the 5-FU-induced diarrhea model on day 9.

the presence of blood (gross or occult blood) and mucus in the stool (1-69). To correctly evaluate these parameters, defecated stools should be collected without damage.

The feces collection methods used in the searched studies were as follows: A) feces collection using the regular cage containing bedding chips (studies without specific descriptions about the feces collection method), B) feces collection on the filter paper placed on the regular cage floor without bedding chips $(20,63,64), \mathrm{C})$ feces collection on the paper towel placed on the bedding chips in the regular cage $(65), \mathrm{D})$ feces collection using the metabolic cage (62), and E) feces collection while holding the mouse in the hand $(19,66)$.

In the present study, the paper towel method devised by the authors was compared with the above-described stool collection methods in terms of the capability of collecting intact stools without damage. Feces collection while holding the mouse in the hand was excluded from the comparison experiments because it was considered inadequate for use in usual experiments dealing with a large number of mice.

When collecting feces by using the regular cage containing bedding chips (A), wet stools were stuck to the bedding chips and damaged. Therefore, it was hard to determine the stool consistency and shape, which are the parameters commonly employed in evaluating the diarrhea score.

Feces collection on the filter paper placed on the regular cage floor without bedding chips (B) and feces collection on the paper towel placed on the bedding chips in the regular cage (C) were considered to be similar methods. Therefore, only the method having a paper towel laid on the cage floor without bedding chips was tested as the representative of the two methods. It was also hard to evaluate the consistency and shape of the feces because of the fecal damage caused by being stepped on by the mouse foot and body.

In feces collection using the fully equipped metabolic cage, only a small fraction of defecated feces having low stickiness (wetness) were collected in the feces collection tube, and the remaining large fraction of feces were stuck to the sliding down side wall of the metabolic cage. The feces collected in the feces collection tube have to be transferred onto a paper towel to assess the diarrhea score. During the transferring process, the feces may be damaged, and therefore unfit for evaluating their consistency and shape, especially when they were entangled together in the small space of the feces collection tube.

On the other hand, the paper towel method collected the feces with little damage compared to the searched feces collection methods. The paper towel method was therefore considered efficient and convenient to evaluate the parameters employed in determining diarrhea scores.

Some previous studies evaluated the size of the water mark (diarrhea mark) generated on the filter paper as a parameter to determine the diarrhea score $(20,63,64)$. 
However, the size of the water mark generated on the paper towel by the same amount of instilled water was larger than that on the filter paper in the present study. This result indicated that the paper towel is more sensitive than the filter paper in detecting the water (wetness or moisture) contained in the stool. This result led us to employ the paper towel instead of the filter paper as a component of the paper towel method. The paper towel is also cheaper than the filter paper. The paper towel method can evaluate the size of the water mark as well as its presence generated by the wet stool. Therefore, the paper towel method can be more sensitive and objective than evaluating the stool consistency/wetness with the naked eyes only or by using the filter paper. These findings indicated that the paper towel method can be preferred when evaluating the stool consistency/wetness.

The paper towel method requires the mouse-dwelling portion of the metabolic cage. However, there are laboratories that do not have metabolic cages. For such laboratories, two modified paper towel methods were devised in the present study. The modified methods no longer require the mouse-dwelling portion of the metabolic cage. They showed to have comparable stool collection functions to the paper towel method in terms of the capability of collecting intact stools without damage.

Many previous studies did not describe feces collection methods employed in evaluating the diarrhea score. They were considered to have used regular cages containing bedding chips in collecting defecated feces. Regardless of the presence of the description, searched feces collection methods did not seem that practical, as confirmed in the present study. Researchers using mouse diarrhea models for the first time may therefore encounter difficulties in collecting intact stools and consequently in evaluating the diarrhea score. Moreover, the grading boundaries of various diarrhea scores are ambiguous, adding more difficulties in evaluating the diarrhea score $(2,5,6,17,22)$. This study was intended to be helpful in those cases.

The most accurate way to assess the diarrhea score would be to monitor the mouse continuously, detect when it is defecating, and evaluate the defecated stool immediately, e.g., the evaluation of the stool being defecated while holding the mouse in the hand $(19,66)$. However, considering that most mouse experiments do not deal with a small number of mice, but a large number of mice, it is not that practical. Another accurate way would be to evaluate the stool in the rectum or the large bowel after sacrificing the mouse (67-69). However, it can only evaluate the diarrhea score once per mouse, and serial evaluations over several days are difficult. There is also the inconvenience of sacrificing the mouse each time for the stool evaluation. Therefore, the paper towel method or modified paper towel methods can be recommended in experiments evaluating the

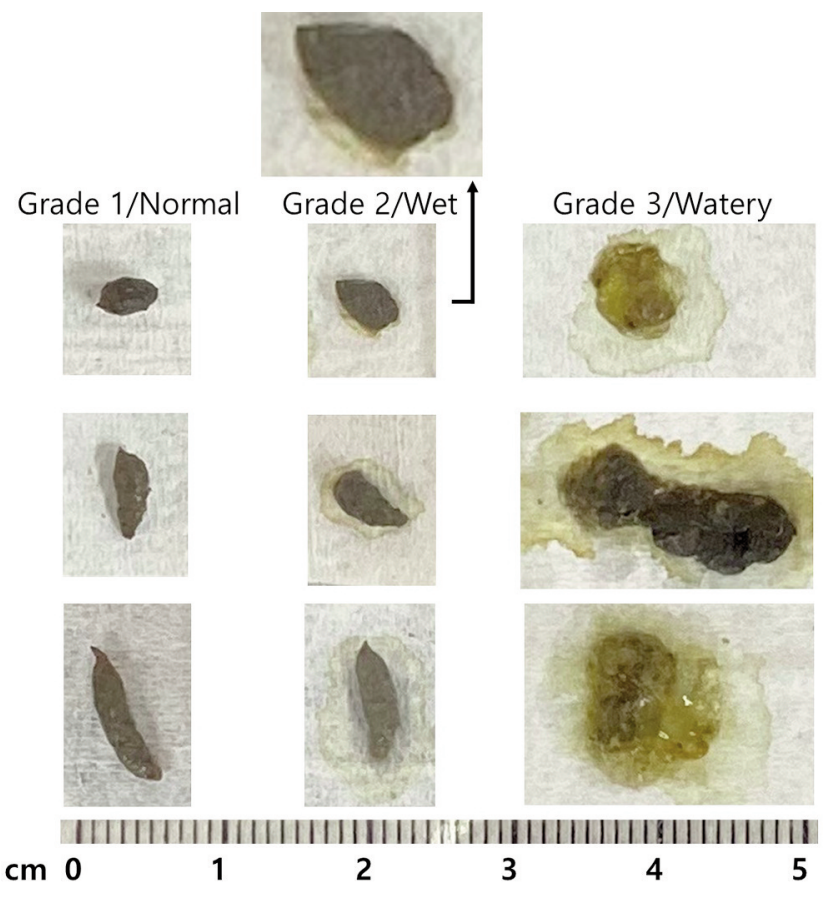

Figure 7. Proposed examples of grade 1/normal (left), grade 2/wet (middle), and grade 3/watery (right) stools. Grade 1/normal stool (normal shaped stool without water mark on the paper towel), grade $2 /$ wet stool (normal shaped stool with water mark beyond the edge of the stool on the paper towel), and grade 3/watery stool (unshaped stool with water mark beyond the edge of the stool on the paper towel or watery diarrhea with scanty formed components). Note the uppermost enlarged case. This stool is considered grade 2 (not grade 1) because it has a water mark slightly larger than the stool margin.

diarrhea score, because feces can be collected for required periods without such inconvenience.

In the searched literature, the number of grades of various diarrhea scores determining the degree of stool consistency ranges from 2 to 5. Examples according to the number of grades are as follows: 2-grade method (normal stool vs. diarrhea stool), 3-grade method (normal stool vs. soft stool vs. watery or very soft stool), 4-grade method (normal stool vs. wet stool vs. loose stool vs. watery stool), and 5-grade method (normal stool $v s$. slightly loose stool $v s$. loose stool $v s$. watery stool $v s$. severe diarrhea). The more the number of grades, the more ambiguous the boundaries between grades. Therefore, it may be hard to obtain reproducible diarrhea scores. Thus, there were studies in which two or more researchers evaluated the diarrhea score blindly for the same stool sample $(19,52,54$, $68,69)$. However, the attempt does not seem efficient.

Therefore, a new grading method was proposed to obtain a more objective diarrhea score in the present study. As the number of grades that distinguish stool consistency increases, the boundaries between grades become more 
ambiguous. The proposal of the 4-grade method or 5-grade method was therefore excluded. Considering a 3-grade method first, the stool consistency can be divided into normal stool, wet stool, and watery stool. A practical procedure for determining the diarrhea score by employing this 3-grade method is proposed as follows: 1) Collect feces using the paper towel method or modified paper towel methods. The duration of stool collection can be determined depending on the frequency of defecation of the employed mouse model. For example, in the present study, feces were collected for $1 \mathrm{~h}$ in the 5-FU-induced diarrhea model and 2 $\mathrm{h}$ in the castor oil-induced diarrhea model. 2) Take a photograph of the paper towel on which the feces are seated. 3) Determine the stool consistency grade by observing the photograph. The definition of each grade of stool consistency proposed by the authors is as follows (Figure 7): grade 1 /normal stool (normal shaped stools without water mark on the paper towel), grade 2/wet stool (normal shaped stools with water mark beyond the edge of the stool on the paper towel), and grade 3/watery stool (unshaped stools with water mark beyond the edge of the stool on the paper towel or watery diarrhea with scanty formed components). In many previous studies, grade 2 or more was regarded as diarrhea (1-69). Researchers who want to employ the 2-grade method can evaluate the stool as follows: grade 1 (normal stool) and grade 2 (wet stool or watery stool).

When grading the stool consistency, one of the two methods (2- and 3-grade methods) can be selected according to the diarrhea pattern of the mouse model employed in each study. Of course, this proposal requires more validation, and the definition and number of grades can be modified according to the characteristics of each study.

In some studies, the diarrhea score was determined by observing the severity of the fur coat staining caused by diarrheal stools $(3,6,8,35,60)$. In many previous studies, the disease activity index (DAI) was employed to evaluate the severity of diarrhea $(2,9,17,24,33)$. DAI is calculated by scoring the grade of the three parameters (stool consistency, stool blood, and body weight) and summing these scores. In some studies, only two of the three parameters, stool consistency and stool blood, were evaluated to determine DAI $(37,40)$. In other studies, the diarrhea index (DI) was employed to evaluate the severity of diarrhea $(20,63,64)$. DI was calculated by multiplying the diarrhea incidence rate (the number of diarrheal feces $\div$ the total number of feces) by the mean loose stool grade. Fecal water content (wet weight - dry weight $)(12,49)$ and fecal friability tested by pressing with tweezers were also used to evaluate the stool consistency $(1,5)$.

\section{Conclusion}

In the present study, the paper towel method and the two modified paper towel methods were devised to collect mouse feces without damage. New modified procedures for evaluating the mouse diarrhea score were also proposed to help researchers who face difficulties in determining the diarrhea score. The results of the present study may be applied to studies employing rat diarrhea models and to studies requiring intact defecated stools with little damage.

\section{Conflicts of Interest}

The Authors have no conflicts of interest to declare in relation to this study.

\section{Authors' Contributions}

S.K.Y., S.W.K., and S.T.L. conceived and designed the experiments. S.K.Y. performed the experiments. S.K.Y., S.W.K., and S.T.L. analyzed the data and wrote the article.

\section{Acknowledgements}

This paper was supported by the fund of Biomedical Research Institute, Jeonbuk National University Hospital, Jeonju, Republic of Korea, which had no role in the design, execution, interpretation, or writing of the study.

\section{References}

1 Takemori H, Hamamoto A, Isogawa K, Ito M, Takagi M, Morino $\mathrm{H}$, Miura $\mathrm{T}$, Oshida $\mathrm{K}$ and Shibata $\mathrm{T}$ : Mouse model of metformin-induced diarrhea. BMJ Open Diabetes Res Care 8(1): e000898, 2020. PMID: 32213489. DOI: 10.1136/bmjdrc-2019000898

2 Nunes NS, Chandran P, Sundby M, Visioli F, da Costa Gonçalves F, Burks SR, Paz AH and Frank JA: Therapeutic ultrasound attenuates DSS-induced colitis through the cholinergic anti-inflammatory pathway. EBioMedicine 45: 495510, 2019. PMID: 31253515. DOI: 10.1016/j.ebiom.2019.06.033

3 Zhang L, Jin Y, Peng J, Chen W, Lisha L and Lin J: Qingjie Fuzheng Granule attenuates 5-fluorouracil-induced intestinal mucosal damage. Biomed Pharmacother 118: 109223, 2019. PMID: 31325706. DOI: 10.1016/j.biopha.2019.109223

4 Lee JM, Yoo IK, Lee JM, Kim SH, Choi HS, Kim ES, Keum B, Seo YS, Jeen YT, Chun HJ, Lee HS, Um SH and Kim CD: Dipeptidyl-peptidase-4 (DPP-4) inhibitor ameliorates 5flurouracil induced intestinal mucositis. BMC Cancer 19(1): 1016, 2019. PMID: 31664952. DOI: 10.1186/s12885-019-6231y

5 Chan YT, Cheung F, Zhang C, Fu B, Tan HY, Norimoto H, Wang $\mathrm{N}$ and Feng Y: Ancient Chinese medicine herbal formula Huanglian Jiedu Decoction as a neoadjuvant treatment of chemotherapy by improving diarrhea and tumor response. Front Pharmacol 11: 252, 2020. PMID: 32210825. DOI: 10.3389/ fphar.2020.00252

6 Xiang DC, Yang JY, Xu YJ, Zhang S, Li M, Zhu C, Zhang CL and Liu D: Protective effect of Andrographolide on 5-Fu induced intestinal mucositis by regulating p38 MAPK signaling pathway. Life Sci 252: 117612, 2020. PMID: 32247004. DOI: 10.1016/j.lfs.2020.117612 
7 Ya-Nan G, Jun W, Hao-Jun Z, Hong-Bing J, Ping L and Xin-Zhu L: Traditional Chinese medicine QPYF as preventive treatment for Clostridium difficile associated diarrhea in a mouse model. Evid Based Complement Alternat Med 2016: 3759819, 2016 PMID: 27999606. DOI: 10.1155/2016/3759819

8 Wang J, Feng W, Zhang S, Chen L, Sheng Y, Tang F, He J, Xu $\mathrm{X}$, Ao $\mathrm{H}$ and Peng C: Ameliorative effect of Atractylodes macrocephala essential oil combined with Panax ginseng total saponins on 5-fluorouracil induced diarrhea is associated with gut microbial modulation. J Ethnopharmacol 238: 111887, 2019. PMID: 31004726. DOI: 10.1016/j.jep.2019.111887

9 Wu ZC, Zhao ZL, Deng JP, Huang JT, Wang YF and Wang ZP: Sanhuang Shu'ai decoction alleviates DSS-induced ulcerative colitis via regulation of gut microbiota, inflammatory mediators and cytokines. Biomed Pharmacother 125: 109934, 2020. PMID: 32058214. DOI: 10.1016/j.biopha.2020.109934

10 Wang L, Tang H, Wang C, Hu Y, Wang S and Shen L: Aquaporin 4 deficiency alleviates experimental colitis in mice. FASEB J 33(8): 8935-8944, 2019. PMID: 31034776. DOI: 10.1096/ fj.201802769RR

11 Rezaei N, Avan A, Pashirzad M, Rahmani F, Moradi Marjaneh R, Behnam-Rassouli R, Shafiee M, Ryzhikov M, Hashemzehi M, Ariakia F, Bahreyni A, Hassanian SM and Khazaei M: Crocin as a novel therapeutic agent against colitis. Drug Chem Toxicol 43(5): 514-521, 2020. PMID: 30714419. DOI: 10.1080/ 01480545.2018 .1527850

12 Zhang Y, Zhang H, Zhang W, Zhang Y, Wang W and Nie L: LncRNA XIST modulates 5-hydroxytrytophan-induced visceral hypersensitivity by epigenetic silencing of the SERT gene in mice with diarrhea-predominant IBS. Cell Signal 73: 109674 2020. PMID: 32446903. DOI: 10.1016/j.cellsig.2020.109674

13 Ni Y, Liu M, Yu H, Chen Y, Liu Y, Chen S, Ruan J, Da A, Zhang $\mathrm{Y}$ and Wang T: Desmethylbellidifolin from Gentianella acuta ameliorate TNBS-induced ulcerative colitis through antispasmodic effect and anti-inflammation. Front Pharmacol 10: 1104, 2019. PMID: 31616306. DOI: 10.3389/fphar.2019.01104

14 Du SY, Huang HF, Li XQ, Zhai LX, Zhu QC, Zheng K, Song X, Xu CS, Li CY, Li Y, He ZD and Xiao HT: Anti-inflammatory properties of uvaol on DSS-induced colitis and LPS-stimulated macrophages. Chin Med 15: 43, 2020. PMID: 32411289. DOI: 10.1186/s13020-020-00322-0

15 Lee AS, Lee KM, Lee JA and Choi I: Peanut shell extract inhibits the development of dextran sulfate sodium (DSS)induced colitis. Int Immunopharmacol 70: 235-240, 2019. PMID: 30851703. DOI: 10.1016/j.intimp.2019.02.040

16 Huang L, Chiang Chiau JS, Cheng ML, Chan WT, Jiang CB, Chang SW, Yeung CY and Lee HC: SCID/NOD mice model for 5-FU induced intestinal mucositis: Safety and effects of probiotics as therapy. Pediatr Neonatol 60(3): 252-260, 2019. PMID: 30150027. DOI: 10.1016/j.pedneo.2018.07.007

17 Chen W, Zhang J, Li C, Pan Q, Wu J, Fan L, Chen C, Huang X, Teng $\mathrm{F}$ and $\mathrm{Zhu} \mathrm{J}$ : Is dextran sulfate sodium a good inducer of acute experimental enteritis? Int J Immunopathol Pharmacol 33: 2058738419843367, 2019. PMID: 30968717. DOI: 10.1177/ 2058738419843367

18 Boeing T, de Souza P, Speca S, Somensi LB, Mariano LNB, Cury BJ, Ferreira Dos Anjos M, Quintão NLM, Dubuqoy L, Desreumax P, da Silva LM and de Andrade SF: Luteolin prevents irinotecan-induced intestinal mucositis in mice through antioxidant and anti-inflammatory properties. Br J Pharmacol
177(10): 2393-2408, 2020. PMID: 31976547. DOI: 10.1111/ bph.14987

19 Bialowas S, Hagbom M, Nordgren J, Karlsson T, Sharma S, Magnusson KE and Svensson L: Rotavirus and Serotonin CrossTalk in Diarrhoea. PLoS One 11(7): e0159660, 2016. PMID: 27459372. DOI: 10.1371/journal.pone .0159660

20 Yao DW, Yu ZZ, Li N, Hou YN, Xu JR and Yang DJ: Coppermodified palygorskite is effective in preventing and treating diarrhea caused by Salmonella typhimurium. J Zhejiang Univ Sci B 18(6): 474-480, 2017. PMID: 28585423. DOI: 10.1631/ jzus.B1600133

21 Chang CW, Liu CY, Lee HC, Huang YH, Li LH, Chiau JC, Wang TE, Chu $\mathrm{CH}$, Shih SC, Tsai $\mathrm{TH}$ and Chen YJ: Lactobacillus casei variety rhamnosus probiotic preventively attenuates 5-Fluorouracil/Oxaliplatin-induced intestinal injury in a syngeneic colorectal cancer model. Front Microbiol 9: 983, 2018. PMID: 29867884. DOI: 10.3389/fmicb.2018.00983

22 Jin X, Yang Y, Bai X, Shi H, Zhang W, Zhang Z, Jia W, Lin J, Liu M and Liu X: Dendritic cells treated by Trichinella spiralis muscle larval excretory/secretory products alleviate TNBSinduced colitis in mice. Int Immunopharmacol 70: 378-386, 2019. PMID: 30852293. DOI: 10.1016/j.intimp.2019.02.028

23 Wei Y, Jiang N, Liu T, Liu C, Xiao W, Liang L, Li T and Yu Y: The comparison of extraction methods of ganjiang decoction based on fingerprint, quantitative analysis and pharmacodynamics. Chin Med 15: 81, 2020. PMID: 32774446. DOI: 10.1186/s13020-020-00355-5

24 Pang J, Ding J, Zhang L, Zhang Y, Yang Y, Bai X, Liu X, Jin X, Guo $\mathrm{H}$, Yang $\mathrm{Y}$ and Liu M: Effect of recombinant serine protease from adult stage of Trichinella spiralis on TNBSinduced experimental colitis in mice. Int Immunopharmacol 86: 106699, 2020. PMID: 32570037. DOI: 10.1016/j.intimp. 2020.106699

25 Mooyottu S, Flock G, Upadhyay A, Upadhyaya I, Maas K and Venkitanarayanan K: Protective effect of carvacrol against gut dysbiosis and Clostridium difficile associated disease in a mouse model. Front Microbiol 8: 625, 2017. PMID: 28484429. DOI: 10.3389/fmicb.2017.00625

26 Yamasaki M, Muraki Y, Nishimoto Y, Murakawa Y and Matsuo T: Fluorescence-labeled liposome accumulation in injured colon of a mouse model of T-cell transfer-mediated inflammatory bowel disease. Biochem Biophys Res Commun 494(1-2): 188193, 2017. PMID: 29037813. DOI: 10.1016/j.bbrc.2017.10.058

27 Grabinger T, Glaus Garzon JF, Hausmann M, Geirnaert A, Lacroix $\mathrm{C}$ and Hennet T: Alleviation of intestinal inflammation by oral supplementation with 2-fucosyllactose in mice. Front Microbiol 10: 1385, 2019. PMID: 31275292. DOI: 10.3389/ fmicb.2019.01385

28 Dong N, Li X, Xue C, Wang C, Xu X, Bi C, Shan A and Li D: Astragalus polysaccharides attenuated inflammation and balanced the gut microflora in mice challenged with Salmonella typhimurium. Int Immunopharmacol 74: 105681, 2019. PMID: 31220694. DOI: 10.1016/j.intimp.2019.105681

29 Gamo K, Okuzono Y, Yabuki M, Ochi T, Sugimura K, Sato Y, Sagara M, Hayashi H, Ishimura Y, Nishimoto Y, Murakawa Y, Shiokawa Z, Gotoh M, Miyazaki T and Ebisuno Y: Gene signature-based approach identified MEK1/2 as a potential target associated with relapse after anti-TNF $\alpha$ treatment for Crohn's disease. Inflamm Bowel Dis 24(6): 1251-1265, 2018. PMID: 29669006. DOI: 10.1093/ibd/izy079 
30 Chen JF, Luo DD, Lin YS, Liu YH, Wu JZ, Yi XQ, Wu Y, Zhang Q, Gao CJ, Cai J and Su ZR: Aqueous extract of Bruguiera gymnorrhiza leaves protects against dextran sulfate sodium induced ulcerative colitis in mice via suppressing NF-kB activation and modulating intestinal microbiota. J Ethnopharmacol 251: 112554, 2020. PMID: 31923541. DOI: 10.1016/j.jep.2020.112554

31 Levit R, Savoy de Giori G, de Moreno de LeBlanc A and LeBlanc JG: Folate-producing lactic acid bacteria reduce inflammation in mice with induced intestinal mucositis. J Appl Microbiol 125(5): 1494-1501, 2018. PMID: 29969527. DOI: 10.1111/jam.14038

32 Amara J, Saliba Y, Hajal J, Smayra V, Bakhos JJ, Sayegh R and Fares N: Circadian rhythm disruption aggravates DSS-induced colitis in mice with fecal calprotectin as a marker of colitis severity. Dig Dis Sci 64(11): 3122-3133, 2019. PMID: 31115725. DOI: 10.1007/s10620-019-05675-7

33 Lin Y, Zheng X, Chen J, Luo D, Xie J, Su Z, Huang X, Yi X, Wei L, Cai J and Sun Z: Protective effect of Bruguiera gymnorrhiza (L.) Lam. fruit on dextran sulfate sodium-induced ulcerative colitis in mice: Role of Keap1/Nrf2 pathway and gut microbiota. Front Pharmacol 10: 1602, 2020. PMID: 32116661. DOI: $10.3389 /$ fphar.2019.01602

34 Somani S, Zambad S and Modi K: Mangiferin attenuates DSS colitis in mice: Molecular docking and in vivo approach. Chem Biol Interact 253: 18-26, 2016. PMID: 27125760. DOI: 10.1016/ j.cbi.2016.04.033

35 Yokota H, Tsuzuki A, Shimada Y, Imai A, Utsumi D, Tsukahara T, Matsumoto M, Amagase K, Iwata K, Nakamura A, YabeNishimura $\mathrm{C}$ and Kato S: NOX1/NADPH oxidase expressed in colonic macrophages contributes to the pathogenesis of colonic inflammation in trinitrobenzene sulfonic acid-induced murine colitis. J Pharmacol Exp Ther 360(1): 192-200, 2017. PMID: 27754929. DOI: 10.1124/jpet.116.235580

36 Liu Z, Xie W, Li M, Teng N, Liang X, Zhang Z, Yang Z and Wang $X$ : Oral administration of polaprezinc attenuates fluorouracil-induced intestinal mucositis in a mouse model. Basic Clin Pharmacol Toxicol 121(6): 480-486, 2017. PMID: 28667794. DOI: $10.1111 / \mathrm{bcpt} .12841$

37 Xue P, Wang L, Xu J, Liu J, Pan X, Zhao Y and Xu H: Temperature-sensitive hydrogel for rectal perfusion improved the therapeutic effect of Kangfuxin liquid on DSS-induced ulcerative colitis mice: The inflammation alleviation and the colonic mucosal barriers repair. Int J Pharm 589: 119846, 2020. PMID: 32891717. DOI: 10.1016/j.ijpharm.2020.119846

38 de Paula-Silva M, Barrios BE, Macció-Maretto L, Sena AA, Farsky SH, Correa SG and Oliani SM: Role of the protein annexin A1 on the efficacy of anti-TNF treatment in a murine model of acute colitis. Biochem Pharmacol 115: 104-113, 2016. PMID: 27343762. DOI: 10.1016/j.bcp.2016.06.012

39 Li Y, Xue M, Yu L, Luo G, Yang H, Jia L, Zeng Y, Li T, Ge S and Xia N: Expression and characterization of a novel truncated rotavirus VP4 for the development of a recombinant rotavirus vaccine. Vaccine 36(16): 2086-2092, 2018. PMID: 29555220. DOI: 10.1016/j.vaccine.2018.03.011

40 Kawade Y, Sakai M, Okamori M, Morita M, Mizushima K, Ueda $\mathrm{T}$, Takagi $\mathrm{T}$, Naito $\mathrm{Y}$, Itoh $\mathrm{Y}$ and Shimada $\mathrm{T}$ : Administration of live, but not inactivated, Faecalibacterium prausnitzii has a preventive effect on dextran sodium sulfate-induced colitis in mice. Mol Med Rep 20(1): 25-32, 2019. PMID: 31115531. DOI: 10.3892/mmr.2019.10234
41 Wu H, Chen QY, Wang WZ, Chu S, Liu XX, Liu YJ, Tan C, Zhu F, Deng SJ, Dong YL, Yu T, Gao F, He HX, Leng XY and Fan H: Compound sophorae decoction enhances intestinal barrier function of dextran sodium sulfate induced colitis via regulating notch signaling pathway in mice. Biomed Pharmacother 133: 110937, 2021. PMID: 33217689. DOI: 10.1016/j.biopha.2020.110937

42 Wang R, Gu X, Dai W, Ye J, Lu F, Chai Y, Fan G, Gonzalez FJ, Duan $G$ and Qi $Y$ : A lipidomics investigation into the intervention of celastrol in experimental colitis. Mol Biosyst 12(5): 1436-1444, 2016. PMID: 27021137. DOI: 10.1039/ c5mb00864f

43 Choo J, Heo G, Kim SJ, Lee Y, Ishigami A, Maruyama N, Chung HY and Im E: Senescence marker protein 30 protects intestinal epithelial cells against inflammation-induced cell death by enhancing Nrf2 activity. Biochim Biophys Acta Mol Basis Dis 1864(12): 3668-3678, 2018. PMID: 30266650. DOI: 10.1016/j.bbadis.2018.09.031

44 Chen L, Zhou Z, Yang Y, Chen N and Xiang H: Therapeutic effect of imiquimod on dextran sulfate sodium-induced ulcerative colitis in mice. PLoS One 12(10): e0186138, 2017. PMID: 29049372. DOI: 10.1371/journal.pone.0186138

45 Das S, Rachagani S, Sheinin Y, Smith LM, Gurumurthy CB, Roy HK and Batra SK: Mice deficient in Muc4 are resistant to experimental colitis and colitis-associated colorectal cancer. Oncogene 35(20): 2645-2654, 2016. PMID: 26364605. DOI: 10.1038/onc.2015.327

46 Zheng L, Zhang YL, Dai YC, Chen X, Chen DL, Dai YT and Tang ZP: Jianpi Qingchang decoction alleviates ulcerative colitis by inhibiting nuclear factor-kB activation. World J Gastroenterol 23(7): 1180-1188, 2017. PMID: 28275298. DOI: 10.3748/ wjg.v23.i7.1180

47 Hoffmann M, Schwertassek U, Seydel A, Weber K, Hauschildt $\mathrm{S}$ and Lehmann J: Therapeutic efficacy of a combined sage and bitter apple phytopharmaceutical in chronic DSS-induced colitis. Sci Rep 7(1): 14214, 2017. PMID: 29079781. DOI: 10.1038/ s41598-017-13985-x

48 Nakagawa T, Mori N, Kajiwara C, Kimura S, Akasaka Y, Ishii Y, Saji $\mathrm{T}$ and Tateda K: Endogenous IL-17 as a factor determining the severity of Clostridium difficile infection in mice. J Med Microbiol 65(8): 821-827, 2016. PMID: 27166143. DOI: $10.1099 / \mathrm{jmm} .0 .000273$

49 Berlin P, Reiner J, Wobar J, Bannert K, Glass Ä, Walter M, Bastian M, Willenberg HS, Vollmar B, Klar E, Seidler U, Lamprecht $\mathrm{G}$ and Witte M: Villus growth, increased intestinal epithelial sodium selectivity, and hyperaldosteronism are mechanisms of adaptation in a murine model of short bowel syndrome. Dig Dis Sci 64(5): 1158-1170, 2019. PMID: 30569336. DOI: 10.1007/s10620-018-5420-x

50 Gupta RA, Motiwala MN, Mahajan UN and Sabre SG: Protective effect of Sesbania grandiflora on acetic acid induced ulcerative colitis in mice by inhibition of TNF- $\alpha$ and IL-6. J Ethnopharmacol 219: 222-232, 2018. PMID: 29530609. DOI: 10.1016/j.jep.2018.02.043

51 You BH, Chae HS, Song J, Ko HW, Chin YW and Choi YH: $\alpha-$ Mangostin ameliorates dextran sulfate sodium-induced colitis through inhibition of NF-kB and MAPK pathways. Int Immunopharmacol 49: 212-221, 2017. PMID: 28601023. DOI: 10.1016/j.intimp.2017.05.040

52 Zhang Y, Yang Z, Gao S, Hamza T, Yfantis HG, Lipsky M and Feng H: The role of purified Clostridium difficile glucosylating 
toxins in disease pathogenesis utilizing a murine cecum injection model. Anaerobe 48: 249-256, 2017. PMID: 29031928. DOI: 10.1016/j.anaerobe.2017.10.006

53 Choi YH, Bae JK, Chae HS, Choi YO, Nhoek P, Choi JS and Chin YW: Isoliquiritigenin ameliorates dextran sulfate sodiuminduced colitis through the inhibition of MAPK pathway. Int Immunopharmacol 31: 223-232, 2016. PMID: 26771170. DOI: 10.1016/j.intimp.2015.12.024

54 Wardill HR, Gibson RJ, Van Sebille YZ, Secombe KR, Coller JK, White IA, Manavis J, Hutchinson MR, Staikopoulos V, Logan RM and Bowen JM: Irinotecan-induced gastrointestinal dysfunction and pain are mediated by common TLR4-dependent mechanisms. Mol Cancer Ther 15(6): 1376-1386, 2016. PMID: 27197307. DOI: 10.1158/1535-7163.MCT-15-0990

55 Liu T, Wang R, Xu H, Song Y and Qi Y: A highly potent and selective histone deacetylase 6 inhibitor prevents DSS-induced colitis in mice. Biol Pharm Bull 40(6): 936-940, 2017. PMID: 28321036. DOI: 10.1248/bpb.b16-01023

56 Choi JH, Chung KS, Jin BR, Cheon SY, Nugroho A, Roh SS and An HJ: Anti-inflammatory effects of an ethanol extract of Aster glehni via inhibition of NF-kB activation in mice with DSSinduced colitis. Food Funct 8(7): 2611-2620, 2017. PMID: 28695925. DOI: $10.1039 / \mathrm{c} 7$ fo00369b

57 Pedrotti LP, Barrios BE, Maccio-Maretto L, Bento AF, Sena AA, Rodriguez-Galán MC, Calixto JB and Correa SG: Systemic IL12 burst expands intestinal T-lymphocyte subsets bearing the $\alpha_{4}$ $\beta_{7}$ integrin in mice. Eur J Immunol 46(1): 70-80, 2016. PMID: 26464149. DOI: $10.1002 /$ eji.201545585

58 Wang J, Tian M, Li W and Hao F: Preventative delivery of IL35 by Lactococcus lactis ameliorates DSS-induced colitis in mice. Appl Microbiol Biotechnol 103(19): 7931-7941, 2019. PMID: 31456001. DOI: 10.1007/s00253-019-10094-9

59 Shelby RD, Tengberg N, Conces M, Olson JK, Navarro JB, Bailey MT, Goodman SD and Besner GE: Development of a standardized scoring system to assess a murine model of Clostridium difficile colitis. J Invest Surg 33(10): 887-895, 2020. PMID: 30892111. DOI: 10.1080/08941939.2019.1571129

60 Pereira VB, Melo AT, Assis-Júnior EM, Wong DV, Brito GA, Almeida PR, Ribeiro RA and Lima-Júnior RC: A new animal model of intestinal mucositis induced by the combination of irinotecan and 5-fluorouracil in mice. Cancer Chemother Pharmacol 77(2): 323-332, 2016. PMID: 26666645. DOI: 10.1007/s00280-015-2938-x

61 Je IG, Lee DG, Jeong DG, Hong D, Yoon JM, Moon JS and Park S: The probiotic, ID-JPL934, attenuates dextran sulfate sodium-induced colitis in mice through inhibition of proinflammatory cytokines expression. J Med Food 21(9): 858865, 2018. PMID: 30036104. DOI: 10.1089/jmf.2017.4152

62 Aguilera-Lizarraga J, Florens MV, Viola MF, Jain P, Decraecker L, Appeltans I, Cuende-Estevez M, Fabre N, Van Beek K, Perna E, Balemans D, Stakenborg N, Theofanous S, Bosmans G, Mondelaers SU, Matteoli G, Ibiza Martínez S, Lopez-Lopez C, Jaramillo-Polanco J, Talavera K, Alpizar YA, Feyerabend TB, Rodewald HR, Farre R, Redegeld FA, Si J, Raes J, Breynaert C, Schrijvers R, Bosteels C, Lambrecht BN, Boyd SD, Hoh RA, Cabooter D, Nelis M, Augustijns P, Hendrix S, Strid J,
Bisschops R, Reed DE, Vanner SJ, Denadai-Souza A, Wouters $\mathrm{MM}$ and Boeckxstaens GE: Local immune response to food antigens drives meal-induced abdominal pain. Nature 590(7844): 151-156, 2021. PMID: 33442055. DOI: 10.1038/s41586-02003118-2

63 Yu J, Zhang Y, Song X, Yang Y, Jia R, Chen X, Sun K, Li L, Zhao X, Cui Q, Fu Q, Zou Y, Li L and Yin Z: Effect of modified Pulsatilla powder on enterotoxigenic Escherichia coli O101induced diarrhea in mice. Evid Based Complement Alternat Med 2017: 3687486, 2017. PMID: 28798800. DOI: 10.1155/ 2017/3687486

64 Lu J, Mao D, Li X, Ma Y, Luan Y, Cao Y and Luan Y: Changes of intestinal microflora diversity in diarrhea model of KM mice and effects of Psidium guajava L. as the treatment agent for diarrhea. J Infect Public Health 13(1): 16-26, 2020. PMID: 31133420. DOI: 10.1016/j.jiph.2019.04.015

65 Taghipour N, Molaei M, Mosaffa N, Rostami-Nejad M, Asadzadeh Aghdaei H, Anissian A, Azimzadeh P and Zali MR: An experimental model of colitis induced by dextran sulfate sodium from acute progresses to chronicity in C57BL/6: correlation between conditions of mice and the environment. Gastroenterol Hepatol Bed Bench 9(1): 45-52, 2016. PMID: 26744614.

66 Sezaki T, Hirata Y, Hagiwara T, Kawamura YI, Okamura T, Takanashi R, Nakano K, Tamura-Nakano M, Burkly LC and Dohi T: Disruption of the TWEAK/Fn14 pathway prevents 5fluorouracil-induced diarrhea in mice. World J Gastroenterol 23(13): 2294-2307, 2017. PMID: 28428709. DOI: 10.3748/wjg. v23.i13.2294

67 Bartoszek A, Makaro A, Bartoszek A, Kordek R, Fichna J and Salaga M: Walnut oil alleviates intestinal inflammation and restores intestinal barrier function in mice. Nutrients 12(5): 1302, 2020. PMID: 32370215. DOI: 10.3390/nu12051302

68 Park BK, Chun E, Choi JJ, Shin Y, Kho YT, Oh SH, Kim SY, Lee TH, Kim TW, Shin E, Do SG and Jin M: Administration of Wasabia koreana ameliorates irritable bowel syndrome-like symptoms in a Zymosan-induced mouse model. J Med Food 20(5): 474-484, 2017. PMID: 28452565. DOI: 10.1089/ jmf 2016.3844

69 Chun E, Yoon S, Parveen A and Jin M: Alleviation of irritable bowel syndrome-like symptoms and control of gut and brain responses with oral administration of Dolichos lablab L. in a mouse model. Nutrients 10(10): 1475, 2018. PMID: 30309025. DOI: $10.3390 /$ nu10101475

70 Yim SK, Kim KM, Lee CH, Song EK, Lee SO, Kim SW, Kim IH, Kim SH, Seo SY and Lee ST: The superoxide dismutase mimetic M40403, improves 5-fluorouracil-induced small intestinal mucositis in a mouse model. In Vivo 35(3): 14851497, 2021. PMID: 33910826. DOI: 10.21873/invivo.12401

Received April 20, 2021

Revised May 20, 2021

Accepted May 21, 2021 